\title{
Nordic Nutrition Recommendations
} 2004 - integrating nutrition and physical activity

\author{
Wulf Becker, Niels Lyhne, Agnes N. Pedersen, Antti Aro, \\ Mikael Fogelholm, Inga Phórsdottir, Jan Alexander, \\ Sigmund A. Anderssen, Helle M. Meltzer and Jan I. Pedersen
}

\section{Abstract}

The 4th edition of the Nordic Nutrition Recommendations, NNR 2004, gives the proportions between energy yielding nutrients, recommended daily intakes (RI) of certain vitamins and minerals, and reference values for energy intakes in different age and sex groups. Recommendations are also given for dietary fibre, salt and alcohol. Recommendations on daily physical activity are now included and interaction with physical activity has been taken into account for the individual nutrient recommendations wherever appropriate. For adults 30 minutes of daily physical activity of at least moderate intensity is recommended. More physical activity (about 60 minutes daily) with a moderate and/or vigorous intensity may be needed for prevention of weight gain. For children a minimum of 60 minutes of physical activity every day is recommended. As in the 3rd edition, the recommendation is to limit of the intake of saturated plus trans fatty acids to about $10 \%$ of the total energy intake $(\mathrm{E} \%)$ and of the total fat intake to $30 \mathrm{E} \%$. The intake of carbohydrate and dietary fibres should increase, while the intake of refined sugars should not exceed $10 \mathrm{E} \%$. The RI for vitamin A (women) has been lowered, while it has been increased for vitamin D (children and adults up to $60 \mathrm{y}$ ), vitamin C (adults) and folate (women of reproductive age; pregnant and lactating women).

NNR is to be used for planning and evaluation of diets, and as a basis for food and nutrition policy, teaching and dietary information.

Keywords: nutrition recommendations; physical activity; vitamins; minerals; Nordic countries

\section{Introduction}

The Nordic countries have for several decades collaborated in setting guidelines for dietary composition and recommended intakes of nutrients. Similarities in dietary habits as well as in the prevalence of diet-related diseases, such as cardiovascular disease, osteoporosis, obesity and diabetes, warranted a focus on the gross composition of the diet, i.e. the intake of fat, carbohydrate and protein as contributors to the total energy intake. Already in 1968 medical societies in Denmark, Finland, Norway, and Sweden published a joint official statement on 'Medical aspects of the diet in the Nordic countries' (Medicinska synpunkter på folkkosten i de nordiska länderna). The statement dealt with the development of dietary habits and the consequences of an unbalanced diet for the development of non-communicable diseases. Recommendations were given both for the proportion of fat in the diet and the fat quality, i.e. a reduced intake of total fat and saturated fatty acids and an increase in polyunsaturated fatty acids. Food-based guidelines were also included, aiming at an increased consumption of fruit, vegetables, potatoes, low-fat milk, lean meat and cereal products, and a limitation of the consumption of sugar and sugar-rich foods.

The first official Nordic Nutrition Recommendations (NNR), issued in 1980, emphasised a reduction in total fat intake to less than $35 \%$ of the energy consumed and an increased intake of carbohydrates and dietary fibre. Subsequent editions of NNR were published in 1989 (2nd edition) and 1996 (3rd edition) and included a further limitation of fat intake to $30 \%$ of energy intake, more detailed recommendations on fat quality and a focus on energy balance. NNR are an important basis for various uses in the area of food, nutrition and health policy, for formulation of food-based dietary guidelines and for diet and health-related campaigns. 
The 4th edition of the Nordic Nutrition Recommendations, NNR 2004, has been produced by a project group nominated by the Working Group on Diet and Nutrition, NKE, under the Nordic Committee of Senior Officials for Food Issues, EK-Livs. The project group was established in 2000.

The project group consisted of Wulf Becker, chair, Sweden; Åsa Brugård Konde and Eva-May Ohlander, secretariat, Sweden; Niels Lyhne and Agnes N. Pedersen, Denmark; Antti Aro and Mikael Fogelholm, Finland; Jan I. Pedersen, Jan Alexander, Sigmund A. Anderssen and Helle Margrete Meltzer, Norway; and Inga Phórsdottir, Iceland. Brittmarie Sandström, Denmark, was a member of the group, but sadly passed away in October 2002. A working group on recommendations for children was established consisting of Inga Phórsdottir, chair, Iceland; Olle Hernell, Sweden; Britt Lande, Norway; Olli Simell, Finland; Kim Fleischer Michaelsen, Denmark; and Åsa Brugård Konde, secretariat, Sweden. The following experts were engaged for specific chapters: Nils-Georg Asp, Sweden (carbohydrates), Ingegerd Johansson, Sweden (caries, fluorine), Rune Blomhoff, Norway (vitamin A, antioxidants), Lars Dragstedt, Denmark (antioxidants), Susanne Højbjerg Bügel, Denmark (copper), Lars Ovesen, Denmark (iodine), Maria Lennernäs, Sweden (eating pattern), and Ingibjörg Gunnarsdóttir, Iceland (pregnancy, lactation). Food-based recommendations were evaluated by a working group consisting of Ellen Trolle, Denmark; Liisa Valsta, Finland; Hólmfríður Phorgeirsdóttir, Iceland; Lars Johansson, Norway; and Heléne Enghardt Barbieri and Wulf Becker, Sweden.

Valuable comments and contributions were received from a large number of nutrition experts, national agencies and institutes in the Nordic countries in response to referrals in 2003 and 2004. A plenary discussion was held at the 8th Nordic Nutrition Conference in Tønsberg, Norway, in June 2004.

The Nordic Nutrition Recommendations NNR 2004 were officially approved by the Nordic Council of Ministers for Fishery, Agriculture, Forestry and Food, at their meeting on the 13th of August 2004.

In this paper, the main recommendations of the 4th edition of NNR 2004 are presented and summarized. Subsequent parts providing the scientific background documentation and some practical aspects are available in the full NNR report. The project group has reviewed and evaluated scientific work, national and international recommendations and expert reports. Changes have been introduced only when strong scientific evidence has evolved since the 3rd edition. A Nordic perspective has been accounted for in setting the recommendations.

In the 4th edition physical activity has been added and interaction with physical activity has been taken into account for the individual nutrient recommendations wherever appropriate. The energy requirements have been thoroughly reviewed and reference weights and physical activity levels updated. Food-based recommendations have also been included, and the texts on eating patterns, antioxidants and breastfeeding have been expanded. Compared to the 3 rd edition, the recommendations regarding the proportions of energy yielding nutrients remain virtually unchanged. The values for recommended daily intakes are in many cases also unchanged.

The recommended intake (RI) of vitamin A (women) has been lowered, while it has been increased for vitamin $\mathrm{D}$ (children and adults up to $60 \mathrm{y}$ ), vitamin $\mathrm{C}$ (adults) and folate (same RI for all women of reproductive age; but increased for pregnant and lactating women). Regarding iron, the RI ranges for women of reproductive age have been replaced by a single value. In many cases the values for infants and children have been derived from adult data using either body weight or energy requirement as a basis for the estimations.

Recommended intakes have been introduced for copper. However, no recommendations are set for biotin, pantothenic acid, chromium, fluorine, manganese and molybdenum due to insufficient data, i.e. no change compared to the $3 \mathrm{rd}$ edition.

The primary aim of the NNR 2004 report is to provide the scientific background for the different recommendations and their application. The report can, in addition, be used as a complement to text books in the field of nutrition, but is not intended to give a comprehensive overview of metabolism, physiology and clinical aspects of each nutrient or topic.

A secondary aim for NNR 2004 is to function as a basis for national recommendations adopted individually by the Nordic countries.

The 4th edition of NNR is published as a Nord report (Nord 2004:013) by the Nordic Council of Ministers. 


\section{Aims and content of NNR}

Nordic Nutrition Recommendations (NNR) are to be interpreted as guidelines for the nutritional composition of a diet which provides a basis for good health. The basis for setting recommendations is defined for each individual nutrient using available scientific evidence. As new scientific knowledge emerges with time, the NNR have to be reassessed when appropriate and should therefore not be regarded as definitive.

NNR are based on the current nutritional situation in the Nordic countries and are to be used as a basis for planning a diet which:

- satisfies the nutritional needs, i.e. covers physiological requirements for growth and function

- is a prerequisite for an overall good health and contributes to a reduction of risk for dietassociated diseases

NNR are primarily valid for groups of healthy individuals. For individuals with disease and for groups with special needs, the dietary composition may have to be adjusted accordingly.

NNR are valid for the average intake over a longer period of time, e.g. over at least a week, since the dietary composition may vary from meal to meal and from day to day. The recommended intakes refer to the amounts of nutrients ingested. Losses during food preparation, cooking etc. have to be taken into account when the values are used for planning diets.

NNR can be used:

- as guidelines for planning diets for groups

- as a basis for teaching and dietary information

- as a basis for food and nutrition policy

- as a basis for evaluation of dietary intake

NNR cover recommendations and criteria to be used in planning diets for groups and in evaluating dietary intakes. The recommendations include the following components.

1) Recommended intake of fat, carbohydrates and protein as a percentage of total energy intake $(\mathrm{E} \%)$. Recommendations on dietary fibre.

2) Recommended intake of vitamins and minerals. The values include a safety margin accounting for variations in requirement and physiological factors influencing the requirement, which makes it likely that a diet containing these amounts will be sufficient and adequate for practically the entire population.

3) Reference values for energy intake.

4) Recommendations for physical activity.

5) Recommendations for salt intake.

6) Recommendations for alcohol consumption.

7) Reference values for evaluation of nutrient intake.

In the complete NNR 2004 report the background and basis of the recommendations and an introduction to the practical uses and applications of NNR are presented as well as the scientific background for establishing recommendations for each of the components included. Some additional topics are also covered, i.e. breastfeeding, food-based dietary guidelines, eating patterns and antioxidants.

\section{Planning diets for groups}

\section{Recommended intake of fat, carbohydrates and protein as a percentage of total energy intake (excluding energy from alcohol)}

Recommendations for adults and children from 2 years of age

Fat

Intake of saturated plus trans fatty acids should be limited to approximately $10 \%$ of the total energy intake $\left(E^{\%} \%\right)$. Trans fatty acids from partially hydrogenated fats should be limited as much as possible.

Cis-monounsaturated fatty acids should provide $10-15 \mathrm{E} \%$ and polyunsaturated fatty acids 5-10 $E^{o} \%$, including approximately $1 \mathrm{E} \%$ from $n-3$ fatty acids.

Fat (calculated as total fat content including glycerol and other lipid components) should provide 25-35 E\%. The population goal is 30 E\% from fat, which should be used for planning purposes.

The fat composition of the diet should be modified, primarily by reducing the intake of both saturated and trans fatty acids. A reduction in the intake of foods rich in saturated fatty acids is generally accompanied by a reduction in the intake of cholesterol. The saturated fatty acids lauric, 
myristic and palmitic acid, trans fatty acids and cholesterol increase the serum LDL-cholesterol concentration, which is a strong risk factor for coronary heart disease. For the prevention of coronary heart disease, it is most important to reduce the intake of these fatty acids. In addition, moderation in total fat intake is important for the prevention of obesity. This makes it possible to increase the consumption of low-fat foods that are rich in nutrients and other compounds that may also be important for the prevention of cardiovascular diseases and cancer.

Essential polyunsaturated n-6 and n-3 fatty acids should provide at least $3 \mathrm{E} \%$, including at least $0.5 \mathrm{E} \%$ from $\mathrm{n}-3$ fatty acids. For pregnant and lactating women the essential fatty acids should contribute at least $5 \mathrm{E} \%$, including $1 \mathrm{E} \%$ from $n-3$ fatty acids. An intake of polyunsaturated fatty acids exceeding $10 \mathrm{E} \%$ is not recommended, because this may theoretically increase the risk of lipid peroxidation. Furthermore, there are no health benefits associated with a higher intake. Cis-monounsaturated fatty acids (oleic acid) are almost as effective in lowering serum LDL-cholesterol concentration as polyunsaturated fatty acids when substituted for saturated fatty acids.

\section{Carbohydrates and dietary fibre}

Carbohydrates $^{1}$ should provide 50-60\% of the total energy intake ( $\left.E^{0} \%\right)$. The population goal is $55 E^{\%} \%$ from carbohydrates, which should be used for planning purposes.

For adults, the intake of dietary fibre should be 25-35 g/d, i.e. approximately $3 \mathrm{~g} / \mathrm{MJ}$.

Refined sugars should not exceed $10 \mathrm{E} \%$.

This recommendation means for most people an increase in the intake of both carbohydrates and dietary fibre. The increase should in the first instance consist of foods naturally rich in carbohydrates and dietary fibre, i.e. cereal products and potatoes, vegetables, fruit and berries, which are also good sources of vitamins and minerals. An adequate balance between carbohydrates and fat in combination with a high fibre content in the diet contributes to a reduced risk of developing overweight and associated diseases. An adequate intake

\footnotetext{
${ }^{1}$ Carbohydrates excluding dietary fibre
}

of dietary fibre reduces the risk of constipation and can most likely contribute to protection against obesity and colon cancer. Intake of appropriate amounts of dietary fibre from a variety of foods is important for children as well. From school age the intake should gradually increase to reach the recommended level during adolescence. To ensure an adequate intake of essential nutrients and dietary fibre, especially in children and adults with a low energy intake, a limitation of the intake of refined sugars $^{2}$ is necessary. Limitation of the intake of refined sugars from drinks may be important to prevent obesity. It is recommended that the intake of refined sugars should not exceed $10 \mathrm{E} \%$. Frequent consumption of foods rich in sugars should be avoided in order to reduce the caries risk.

\section{Protein}

Protein should provide 10-20\% of the total energy intake $\left(E^{o} \%\right)$. The population goal is $15 E^{o} \%$ from protein, which should be used for planning purposes.

Protein might provide less than $10 \mathrm{E} \%$, but in order to achieve a varied diet and according to Nordic dietary habits the recommendation is $15 \mathrm{E} \%$ for planning purposes. This intake of protein should more than adequately meet the requirements for essential amino acids.

At very low energy intakes $(<6.5 \mathrm{MJ} / \mathrm{d})$, a protein content providing more than $15 \mathrm{E} \%$ may be necessary for planning purposes.

Recommendations for children up to 2 years of age

Exclusive breastfeeding is recommended for infants during the first 6 months. Recommendations for intake of energy yielding nutrients for children 6-23 months are given in Table 1. The energy percent from fat should decline successively from the high level during the first year of life to reach the level recommended for children and adults at the age of 2 years. During the same period protein intake should increase from about $5 \mathrm{E} \%$ (the level in breastmilk) to the recommended content of 10-20 $\mathrm{E} \%$ for older children and adults.

\footnotetext{
${ }^{2}$ Refined sugars include sucrose, glucose, fructose, starch hydrolysates (glucose syrup, high-fructose syrup) and other isolated sugar preparations such as food components used as such or added during food preparation and manufacturing.
} 
Table I. Recommended intake of protein, fat and carbohydrates expressed as $g$ per $\mathrm{MJ}$ and as $\mathrm{E} \%$ for children 6-23 months ${ }^{\mathrm{a}}$. Within the age intervals, a gradual reduction in fat intake is recommended throughout the period from the highest value to the lowest, with a corresponding increase in carbohydrates

\begin{tabular}{lcc}
\hline & g per MJ & $\begin{array}{l}\text { Energy } \\
\text { percent (E\%) }\end{array}$ \\
\hline $\begin{array}{l}\text { 6-II months } \\
\text { Protein }\end{array}$ & $4-9$ & $7-15$ \\
Fat & $8-12$ & $30-45$ \\
Carbohydrates & & $45-60$ \\
12-23 months & & \\
Protein & $6-9$ & $10-15$ \\
Fat & $8-9$ & $30-35$ \\
Carbohydrates & & $50-55$ \\
\hline
\end{tabular}

${ }^{a}$ As exclusive breastfeeding is the preferable source of nutrition for infants $<6$ months, no recommendations for fat, protein and carbohydrate intake are given. For non-breastfed infants, it is recommended that the values for infant formula proposed by the European Commission Scientific Committee for Food (2003) be used. If complementary feeding has started at $4-5$ months, the intakes recommended for 6 - 11 month old infants should be used.

b Intake of refined sugars should not exceed 10 E\%.

n-6 fatty acids should contribute at least $4 \%$ of the total energy intake (E\%) for children 6-11 months, and 3 E\% for children 12-23 months of age. $n$-3 fatty acids should contribute at least $1 \mathrm{E}^{\mathrm{o}} \mathrm{O}$ for children 6-11 months and $0.5 \mathrm{E} \%$ for children 12-23 months.

During the first year, the intake of trans fatty acids from partially hydrogenated fats should be kept as low as possible.

From 12 months the recommendation for older children and adults on saturated and trans fatty acids should be used.

Recommended intake of vitamins and minerals The recommended intake (RI) of certain vitamins and minerals, expressed as average daily intake over time, is given in Table 2. The values for recommended intakes are intended for planning diets for groups of subjects of the specified age intervals. The values include a margin accounting for variations in requirement and physiological factors influencing the requirement, which makes it likely that a diet containing these amounts will be sufficient and adequate for practically the entire population. NNR do not cover all known essential nutrients, since the scientific basis for establishing recommendations was considered incomplete for some nutrients.

\section{Recommendations for planning diets for heterogeneous groups}

In planning diets for groups with a heterogeneous age and sex distribution, the amounts of nutrients per MJ given in Table 3 are recommended. For each nutrient, the figures are based on the age and sex category of individuals 6-60 years old, for which the highest nutrient density is necessary to meet the requirements. These recommendations are not primarily aimed at pregnant and lactating women, nor at adult diets with a low energy level, i.e. less than $8 \mathrm{MJ}$ per day. Furthermore, they are less applicable for planning diets with an energy level above $12 \mathrm{MJ}$ per day, in which a lower density of many nutrients is sufficient.

A very low energy intake is defined as an energy intake below $6.5 \mathrm{MJ} / \mathrm{d}$ as a minimum daily energy intake necessary for providing adequate amounts of micronutrients from the diet. An energy intake of $6.5-8 \mathrm{MJ}$ is considered a low energy intake with an increased risk of an insufficient intake of micronutrients.

A very low energy intake is related to either a very low physical activity level and/or to a low body weight. Low body weight is related to small muscle mass and thereby to low energy expenditure. Among healthy subjects, an actual very low habitual energy intake is probably rare - even among very inactive elderly subjects with physical activity level (PAL) of 1.4, the estimated energy requirements is 7-8 MJ/d. The age-related decrease in energy expenditure may result in very low energy intake in elderly subjects. Very low energy intake is also found among persons on slimming diets and among subjects with eating disorders, food intolerances, etc. When calculating the nutrient density for groups with low energy intake/requirement using RI in Table 2, the nutrient density may become unrealistically high. In that case the recommended nutrient density per MJ from Table 3 should be followed and supplementation with a multi vitaminmineral tablet should be considered. For groups with a very low energy intake, the diet should always be supplemented with a multi vitamin-mineral tablet. The most effective way to prevent low and very low energy intake is to increase the physical activity level.

\section{Reference values for energy intake in groups}

Both excessive and insufficient energy intake in relation to requirements, lead in the long term to 
Table 2. Recommended intake of certain nutrients, expressed as average daily intake over time, for use in planning diets for groups ${ }^{\mathrm{a}}$. The requirements are lower for almost all individuals

\begin{tabular}{|c|c|c|c|c|c|c|c|c|c|c|}
\hline Age years & $\begin{array}{l}\text { Vit. A } \\
\text { RE }^{c}\end{array}$ & $\begin{array}{l}\text { Vit. } D^{d} \\
\mu g\end{array}$ & $\begin{array}{l}\text { Vit. E } \\
\alpha-\mathrm{TE}^{\mathrm{e}}\end{array}$ & $\begin{array}{l}\text { Thiamin } \\
\text { mg }\end{array}$ & $\begin{array}{l}\text { Riboflavin } \\
\text { mg }\end{array}$ & $\begin{array}{l}\text { Niacin } \\
N^{f}\end{array}$ & $\begin{array}{l}\text { Vit. } B_{6} \\
\mathrm{mg}\end{array}$ & $\begin{array}{l}\text { Folate } \\
\mu \mathrm{g}\end{array}$ & $\begin{array}{l}\text { Vit. } B_{12} \\
\mu g\end{array}$ & $\begin{array}{l}\text { Vit C } \\
\text { mg }\end{array}$ \\
\hline$<6 \mathrm{mo}^{\mathrm{b}}$ & - & - & - & - & - & - & - & - & - & - \\
\hline $6-11 \mathrm{mo}$ & 300 & 10 & 3 & 0.4 & 0.5 & 5 & 0.4 & 50 & 0.5 & 20 \\
\hline $12-23 \mathrm{mo}$ & 300 & 10 & 4 & 0.5 & 0.6 & 7 & 0.5 & 60 & 0.6 & 25 \\
\hline $2-5 y$ & 350 & 7.5 & 5 & 0.6 & 0.7 & 9 & 0.7 & 80 & 0.8 & 30 \\
\hline $6-9 y$ & 400 & 7.5 & 6 & 0.9 & 1.1 & 12 & 1.0 & 130 & 1.3 & 40 \\
\hline \multicolumn{11}{|l|}{ Males } \\
\hline $10-13$ & 600 & 7.5 & 8 & 1.2 & 1.4 & 16 & 1.3 & 200 & 2.0 & 50 \\
\hline $14-17$ & 900 & 7.5 & 10 & 1.5 & 1.7 & 20 & 1.6 & 300 & 2.0 & 75 \\
\hline $18-30$ & 900 & 7.5 & 10 & 1.5 & 1.7 & 20 & 1.6 & 300 & 2.0 & 75 \\
\hline $31-60$ & 900 & 7.5 & 10 & 1.4 & 1.7 & 19 & 1.6 & 300 & 2.0 & 75 \\
\hline $6 I-74$ & 900 & 10 & 10 & 1.3 & 1.5 & 17 & 1.6 & 300 & 2.0 & 75 \\
\hline$\geq 75$ & 900 & 10 & 10 & 1.2 & 1.3 & 15 & 1.6 & 300 & 2.0 & 75 \\
\hline \multicolumn{11}{|l|}{ Females } \\
\hline $10-13$ & 600 & 7.5 & 7 & 1.0 & 1.2 & 14 & 1.1 & 200 & 2.0 & 50 \\
\hline $14-17$ & 700 & 7.5 & 8 & 1.2 & 1.3 & 15 & 1.3 & 300 & 2.0 & 75 \\
\hline $18-30$ & 700 & 7.5 & 8 & 1.1 & 1.3 & 15 & 1.3 & 400 & 2.0 & 75 \\
\hline $31-60$ & 700 & 7.5 & 8 & 1.1 & 1.3 & 15 & 1.2 & $300^{g}$ & 2.0 & 75 \\
\hline $61-74$ & 700 & 10 & 8 & 1.0 & 1.2 & 14 & 1.2 & 300 & 2.0 & 75 \\
\hline$\geq 75$ & 700 & 10 & 8 & 1.0 & 1.2 & 13 & 1.2 & 300 & 2.0 & 75 \\
\hline Pregnant & 800 & 10 & 10 & 1.5 & 1.6 & 17 & 1.5 & 500 & 2.0 & 85 \\
\hline Lactating & 1100 & 10 & 11 & 1.6 & 1.7 & 20 & 1.6 & 500 & 2.6 & 100 \\
\hline Age years & $\begin{array}{l}\text { Calcium } \\
\mathrm{mg}\end{array}$ & $\begin{array}{l}\text { Phosphorus } \\
\text { mg }\end{array}$ & $\begin{array}{l}\text { Potassium } \\
\text { g }\end{array}$ & $\begin{array}{l}\text { Magnesium } \\
\mathrm{mg}\end{array}$ & $\begin{array}{l}\text { Iron } \\
\text { mg }\end{array}$ & $\begin{array}{l}Z_{\text {Zinc }}{ }^{\prime} \\
\text { mg }\end{array}$ & $\begin{array}{l}\text { Copper } \\
\text { mg }\end{array}$ & $\begin{array}{l}\text { lodine } \\
\mu \mathrm{g}\end{array}$ & $\begin{array}{l}\text { Selenium } \\
\mu \mathrm{g}\end{array}$ & \\
\hline$<6 \mathrm{mo}^{\mathrm{b}}$ & - & - & - & - & - & - & - & - & - & \\
\hline $6-11 \mathrm{mo}$ & 540 & 420 & 1.1 & 80 & 8 & 5 & 0.3 & 50 & 15 & \\
\hline $12-23 \mathrm{mo}$ & 600 & 470 & 1.4 & 85 & 8 & 5 & 0.3 & 70 & 20 & \\
\hline $2-5 y$ & 600 & 470 & 1.8 & 120 & 8 & 6 & 0.4 & 90 & 25 & \\
\hline $6-9 y$ & 700 & 540 & 2.0 & 200 & 9 & 7 & 0.5 & 120 & 30 & \\
\hline \multicolumn{11}{|l|}{ Males } \\
\hline $10-13$ & 900 & 700 & 3.3 & 280 & 11 & 11 & 0.7 & 150 & 40 & \\
\hline $14-17$ & 900 & 700 & 3.5 & 350 & 11 & 12 & 0.9 & 150 & 50 & \\
\hline $18-30$ & $800^{\mathrm{j}}$ & $600^{\mathrm{i}}$ & 3.5 & 350 & 9 & 9 & 0.9 & 150 & 50 & \\
\hline $31-60$ & 800 & 600 & 3.5 & 350 & 9 & 9 & 0.9 & 150 & 50 & \\
\hline $61-74$ & 800 & 600 & 3.5 & 350 & 9 & 9 & 0.9 & 150 & 50 & \\
\hline$\geq 75$ & 800 & 600 & 3.5 & 350 & 9 & 9 & 0.9 & 150 & 50 & \\
\hline \multicolumn{11}{|l|}{ Females } \\
\hline $10-13$ & 900 & 700 & 2.9 & 280 & 11 & 8 & 0.7 & 150 & 35 & \\
\hline $14-17$ & 900 & 700 & 3.1 & 280 & $15^{1}$ & 9 & 0.9 & 150 & 40 & \\
\hline $18-30$ & $800^{\mathrm{j}}$ & $600^{\mathrm{i}}$ & 3.1 & 280 & $15^{1}$ & 7 & 0.9 & 150 & 40 & \\
\hline $31-60$ & 800 & 600 & 3.1 & 280 & $15\left(9^{m}\right)$ & 7 & 0.9 & 150 & 40 & \\
\hline $6 I-74$ & $800^{k}$ & 600 & 3.1 & 280 & 9 & 7 & 0.9 & 150 & 40 & \\
\hline$\geq 75$ & $800^{k}$ & 600 & 3.1 & 280 & 9 & 7 & 0.9 & 150 & 40 & \\
\hline Pregnant & 900 & 700 & 3.1 & 280 & $-^{\mathrm{n}}$ & 9 & 1.0 & 175 & 55 & \\
\hline Lactating & 900 & 900 & 3.1 & 280 & 15 & 11 & 1.3 & 200 & 55 & \\
\hline
\end{tabular}

${ }^{a}$ Refers to the consumed amount, i.e. changes during preparation, cooking etc. must be accounted for.

bexclusive breastfeeding is the preferable source of nutrition for infants during the first six months of life. Therefore, recommendations for single nutrients are not given for infants $<6$ months. If breastfeeding is not possible, infant formula composed to serve as the only food for infants should be given (Scientific Committee for Food, 2003). If complementary feeding has started at 4-5 months, the recommended intakes for 6-11 month old infants should be used.

${ }^{\mathrm{c}}$ Retinol equivalents; I retinol equivalent $(\mathrm{RE})=\mathrm{I} \mu \mathrm{g}$ retinol $=12 \mu \mathrm{g} \beta$-carotene.

${ }^{\mathrm{d}}$ From 4 weeks of age, infants should receive $10 \mu \mathrm{g}$ vitamin $\mathrm{D}$ per day as a supplement. Elderly people with little or no sun exposure should receive a supplement of $10 \mu \mathrm{g}$ 
vitamin $D_{3}$ per day in addition to the dietary intake.

${ }^{\mathrm{e}} \alpha$-tocopherol equivalents; I $\alpha$-tocopherol equivalent $(\alpha$-TE) $=$ I mg RRR- $\alpha$-tocopherol.

${ }^{\mathrm{f}}$ Niacin equivalent; I niacin equivalent $(\mathrm{NE})=\mathrm{I} \mathrm{mg}$ niacin $=60 \mathrm{mg}$ tryptophan.

${ }^{g}$ Women of reproductive age are recommended an intake of $400 \mu \mathrm{g} / \mathrm{d}$.

${ }^{\mathrm{h}}$ The composition of the meal influences the utilization of dietary iron. The availability increases if the diet contains abundant amounts of vitamin $\mathrm{C}$ and meat or fish daily, while it is decreased at simultaneous intake of e.g. polyphenols or phytic acid.

'The utilization of zinc is negatively influenced by phytic acid and positively by animal protein. The recommended intakes are valid for a mixed animal/vegetable diet. For vegetarian cereal-based diets, a $25-30 \%$ higher intake is recommended.

'i 8 - 20 olds are recommended $900 \mathrm{mg}$ calcium and $700 \mathrm{mg}$ phosphorus per day.

kSupplementation with 500-1000 mg calcium per day may possibly, to some degree, delay age-related bone loss.

'Menstrual flow and its associated iron losses may vary considerably among women. This means that some women require a larger iron supply than others. At an availability of $15 \%, 15 \mathrm{mg} / \mathrm{d}$ will cover the requirement of $90 \%$ of women in fertile ages. Some women require more iron than the habitual diet can supply.

${ }^{\mathrm{m}}$ Recommended intake for post-menopausal women is $9 \mathrm{mg}$ per day.

nIron balance during pregnancy requires iron stores of approximately $500 \mathrm{mg}$ at the start of pregnancy. The physiological need of some women for iron cannot be satisfied during the last two thirds of pregnancy with food only, and supplemental iron is therefore needed.

negative consequences for health. The individual's energy intake and expenditure should therefore be equal at adult age.

In Table 4, reference values are given for energy intake for groups of adults at two different physical activity levels. An active lifestyle, corresponding to PAL 1.8, is considered desirable for maintaining good health. An activity level of PAL 1.6 corresponds to a lifestyle with sedentary work and limited physical activity level during leisure time. The reference body weights used for calculation are based on Nordic populations. The original weights have been corrected so that all individuals fall

Table 3. Recommended nutrient density to be used for planning diets for groups of individuals $6-60$ years of age with a heterogeneous age and sex distribution. The values are adapted to the reference person requiring the highest dietary nutrient density

\begin{tabular}{lc}
\hline & Content per MJ \\
\hline Vitamin A RE & 80 \\
Vitamin D $\mu \mathrm{g}$ & 1.0 \\
Vitamin E $\alpha$-TE & 0.9 \\
Thiamin $\mathrm{mg}$ & 0.12 \\
Riboflavin mg & 0.14 \\
Niacin NE & 1.6 \\
Vitamin $\mathrm{B}_{6} \mathrm{mg}$ & 0.13 \\
Folate $\mu \mathrm{g}$ & 45 \\
Vitamin $\mathrm{B}_{12} \mu \mathrm{g}$ & 0.2 \\
Vitamin $\mathrm{C} \mathrm{mg}$ & 8 \\
Calcium $\mathrm{mg}$ & 100 \\
Phosphorus mg & 80 \\
Potassium g & 0.35 \\
Magnesium mg & 35 \\
Iron mg & 1.6 \\
Zinc mg & 1.1 \\
Copper mg & 0.1 \\
lodine $\mu \mathrm{g}$ & 17 \\
Selenium $\mu \mathrm{g}$ & 4 \\
\hline
\end{tabular}

within the normal of Body Mass Index (BMI) range (18.5-25).

Individual recommendations for energy intake cannot be given due to the large variation between individuals with respect to metabolic rate, body composition and degree of physical activity.

Table 5 contains reference values for energy intakes in groups of children. The reference values for energy requirements in healthy infants and children up to 6 years are based on data from studies using the doubly labelled water technique. For children 6-17 years, the reference values are based on total energy expenditure using estimations of the basal metabolic rate (BMR) and physical activity level (PAL), with values for different activity levels from 10 to 17 years.

\section{Recommendations on physical activity}

Adequate physical activity contributes to the prevention of lifestyle-related diseases such as cardiovascular disease, osteoporosis and certain types of cancer. Daily physical activity is therefore recommended as part of a healthy lifestyle, together with a balanced diet.

\section{Children and adolescents}

There should be a minimum of 60 minutes of physical activity every day. The activity can probably be divided into shorter intervals of physical activity during the course of the day. Activities should be as diverse as possible in order to provide optimal opportunities for developing all aspects of physical fitness including cardio-respiratory fitness, muscle strength, flexibility, speed, mobility, reaction time and coordination. 
Table 4. Reference values for energy intakes in groups of adults with sedentary and active lifestyle ${ }^{a}$

\begin{tabular}{|c|c|c|c|c|}
\hline Sex and age & Body weight $^{\mathbf{b}}$ & REE $^{c}$ & $\begin{array}{l}\text { Sedentary } \\
\text { Sedentary work and } \\
\text { limited physical activity in } \\
\text { leisure time } \\
\left(\mathrm{PAL}^{\mathrm{d}}=1.6\right)\end{array}$ & $\begin{array}{l}\text { Active } \\
\text { Sedentary work and regular } \\
\text { physical activity in leisure time } \\
\left(\text { PAL }^{\mathrm{d}}=1.8\right)\end{array}$ \\
\hline Men & $\mathrm{kg}$ & $\mathrm{MJ} /$ day & $\mathrm{MJ} /$ day & MJ/day \\
\hline $18-30 y$ & 76 & 7.7 & 12.3 & 13.8 \\
\hline $31-60 y$ & 77 & 7.4 & 11.8 & 13.3 \\
\hline $61-74 y$ & 74 & 6.6 & 10.6 & 12.0 \\
\hline$>75 y$ & 73 & 6.0 & 9.6 & 10.8 \\
\hline \multicolumn{5}{|l|}{ Women $^{f}$} \\
\hline $18-30 y$ & 62 & 5.9 & 9.4 & 10.7 \\
\hline $31-60 y$ & 63 & 5.8 & 9.2 & 10.4 \\
\hline $61-74 y$ & 63 & 5.3 & 8.5 & 9.5 \\
\hline$>75 \mathrm{y}$ & 62 & 5.1 & 8.2 & 9.3 \\
\hline
\end{tabular}

${ }^{a}$ It should be noted that these estimations have a large standard error due to inaccuracy in estimation of both REE and PAL. Therefore, the results should be used only for estimation on group level.

${ }^{b}$ Rounded values. The estimated reference weights are based on mean population weights in Denmark, Sweden and Finland, with adjustments for individuals outside BMI range 18.5-25. The values in the tables are thus estimations assuming that all individuals are at normal weight.

${ }^{\mathrm{C}} \mathrm{REE}=$ resting energy expenditure.

${ }^{\mathrm{d}} \mathrm{PAL}=$ physical activity level; total energy expenditure divided by basal metabolism (BMR).

${ }^{e}$ Corresponding to an energy expenditure of 60 minutes brisk walking daily.

fDuring pregnancy the energy requirement increases, mainly during the second and third trimesters. An increase in energy intake of approximately I.5 MJ/d in the second trimester and $2 \mathrm{MJ} / \mathrm{d}$ in the third, is applicable for both activity levels provided that the level ( 1.6 or 1.8 ) is unchanged. During lactation the energy requirement increases by approximately $2 \mathrm{MJ} / \mathrm{d}$ for the reference woman provided that the level of physical activity is unchanged. For many pregnant and lactating women, the increased energy requirement is compensated for by a decreased amount of physical activity.

\section{Adults}

The adult population should undertake a minimum of 30 minutes of daily physical activity of moderate

Table 5. Reference values for energy intakes in groups of children

\begin{tabular}{lll}
\hline Age & Average weight $^{\mathrm{a}} \mathbf{k g}$ & $\begin{array}{l}\text { Estimated energy } \\
\text { requirements }^{\mathrm{b}} \text { Mj/d }\end{array}$ \\
\hline $6-11 \mathrm{mo}$ & 9.1 & 3.2 \\
$12-23 \mathrm{mo}$ & 11.6 & 4.1 \\
$2-5$ y & 16.1 & 5.3 \\
$6-9$ y & 25.2 & 7.7 \\
Boys & & \\
$10-13$ y & 37.5 & 9.8 \\
$14-17$ y & 57.0 & 12.3 \\
Girls & & \\
$10-13$ y & 38.3 & 8.6 \\
$14-17$ y & 53.5 & 9.6 \\
\hline
\end{tabular}

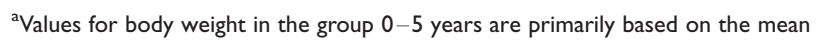
of reference values from Denmark, Finland, Norway and Sweden. Recent values for growth at school age show increasing weight to height and a prevalence of overweight, therefore values for the age group 6-17 y are based on mean values from $1973-1977$.

bValues for children 10-17 y are based on PAL I.75/I.80 for boys and I.65/I.70 for girls. intensity and/or vigorous intensity corresponding to an energy expenditure of about $630 \mathrm{~kJ}$. This should be in addition to the energy expenditure through normal inactive living. The activity can probably be divided into shorter intervals of physical activity during the course of the day, for instance intervals lasting about 10 minutes. An increase in activity beyond this duration and intensity will yield additional benefits. More physical activity (about 60 minutes daily) with a moderate and/or vigorous intensity may be needed for prevention of weight gain.

\section{Recommendations on salt intake}

A gradual reduction in the intake of sodium as sodium chloride is desirable. The population target is $6 \mathrm{~g} / \mathrm{d}$ salt for women and $7 \mathrm{~g} / \mathrm{d}$ for men, corresponding to 2.3 and $2.8 \mathrm{~g} / \mathrm{d}$ of sodium, respectively. A further decrease to 5-6 g salt per day may have additional benefits.

The salt intake of children should also be limited and for children below 2 years of age the sodium density, expressed as salt, should not exceed 
$0.5 \mathrm{~g} / \mathrm{MJ}$, in order to prevent children becoming accustomed to a diet with a high salt content.

\section{Recommendations on consumption of alcohol} The consumption of alcohol should not exceed approximately $10 \mathrm{~g}$ alcohol per day for women and $20 \mathrm{~g}$ per day for men. The energy contribution from alcohol should not exceed $5 \mathrm{E} \%$ in adults. Pregnant and lactating women, children and adolescents are recommended to abstain from alcohol.

\section{Reference values for evaluation of nutrient intake}

\section{Values for evaluating the adequacy of intake of} vitamins and minerals

Table 6 gives values for the estimated average requirement (AR) and lower limit of intake (LI) for certain vitamins and minerals. The values are intended only for use in assessing results from dietary surveys. Before comparing intake data with

Table 6. Estimated average requirement (AR) and lower limit of intake (LI) for certain vitamins and minerals for adults. The values are intended for use only in assessing results from dietary surveys. Long-term intakes below the $\mathrm{LI}$ are associated with an increased risk of developing deficiency symptoms. On the other hand, an intake of nutrients above these values is no guarantee that deficiency symptoms could not occur in single individuals

\begin{tabular}{|c|c|c|c|c|}
\hline \multirow[t]{2}{*}{ Nutrient } & \multicolumn{2}{|c|}{ Men } & \multicolumn{2}{|c|}{ Women } \\
\hline & LI & AR & LI & AR \\
\hline Vitamin A RE & 500 & 600 & 400 & 500 \\
\hline Vitamin D $\mu g$ & $2.5^{\mathrm{a}}$ & - & $2.5^{\mathrm{a}}$ & - \\
\hline Vitamin $\mathrm{E} \alpha-\mathrm{TE}$ & 4 & 6 & 3 & 5 \\
\hline Thiamin mg & 0.6 & 1.2 & 0.5 & 0.9 \\
\hline Riboflavin mg & 0.8 & 1.4 & 0.8 & 1.1 \\
\hline Niacin NE & 12 & 15 & 9 & 12 \\
\hline Vitamin $\mathrm{B}_{6} \mathrm{mg}$ & 1.0 & 1.3 & 0.8 & 1.0 \\
\hline Folate $\mu \mathrm{g}$ & 100 & 200 & 100 & 200 \\
\hline Vitamin $B_{12} \mu g$ & I & 1.4 & I & 1.4 \\
\hline Vitamin C mg & 10 & 60 & 10 & 50 \\
\hline Calcium mg & 400 & - & 400 & - \\
\hline Phosphorus mg & 300 & 450 & 300 & 450 \\
\hline Potassium g & 1.6 & - & 1.6 & - \\
\hline Iron mg & 7 & 7 & $(5)^{b, c}$ & $10(6)^{b}$ \\
\hline Zinc mg & 5 & 6 & 4 & 5 \\
\hline Copper mg & 0.4 & 0.7 & 0.4 & 0.7 \\
\hline lodine $\mu \mathrm{g}$ & 70 & 100 & 70 & 100 \\
\hline Selenium $\mu \mathrm{g}$ & 20 & 35 & 20 & 30 \\
\hline
\end{tabular}

aprimarily for individuals $>60$ years of age.

${ }^{b}()$ Refers to post menopausal women.

${ }^{\mathrm{C}} \mathrm{A}$ lower limit cannot be given for women of fertile age without considering the woman's iron status (determined by clinical-chemical/biochemical methods).
Table 7. Estimated upper levels (UL) for average daily intake of certain nutrients for adults. For certain nutrients, prolonged intakes above these levels can induce a risk of toxic effects (e.g. preformed vitamin A, vitamin D, iron and iodine), while for other nutrients the negative effects are of a milder nature. The values are primarily to be used for the evaluation of intakes by single adult individuals. UL values do not necessarily apply in cases of prescribed supplementation under medical supervision

\begin{tabular}{|c|c|}
\hline Nutrient & $\begin{array}{l}\text { Upper intake } \\
\text { level per day }\end{array}$ \\
\hline Preformed vitamin $\mathrm{A}^{\mathrm{a}} \mu \mathrm{g}$ & $3000^{b}$ \\
\hline Vitamin D $\mu \mathrm{g}$ & 50 \\
\hline Vitamin $\mathrm{E}^{\mathrm{c}} \alpha$-TE & 300 \\
\hline \multicolumn{2}{|l|}{ Niacin $^{c}$} \\
\hline nicotinic acid $\mathrm{mg}$ & $10^{d}$ \\
\hline nicotinamide $\mathrm{mg}$ & 900 \\
\hline Vitamin $B_{6}^{c} \mathrm{mg}$ & 25 \\
\hline Folic acid ${ }^{c} \mu g$ & 1000 \\
\hline Vitamin C mg & 1000 \\
\hline Potassium $^{c} \mathrm{~g}$ & 3.7 \\
\hline Calcium mg & 2500 \\
\hline Phosphorus mg & 5000 \\
\hline Iron mg & $25^{\mathrm{e}}$ \\
\hline Zinc mg & 25 \\
\hline lodine $\mu g$ & 600 \\
\hline Selenium $\mu \mathrm{g}$ & 300 \\
\hline
\end{tabular}

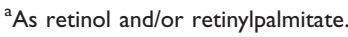

bIntake of retinol in the form of supplements above $3000 \mu \mathrm{g} / \mathrm{d}$ in pregnant women has been associated with an increased risk of foetal malformations. The upper tolerable level may not adequately address the possible risk of bone fracture in vulnerable groups. Postmenopausal women who are at greater risk for osteoporosis and bone fractures should therefore restrict their intake to $1500 \mu \mathrm{g} / \mathrm{d}$.

In the form of supplements and fortification only.

${ }^{\mathrm{d}}$ Not applicable to pregnant and lactating women.

e $10 \mathrm{mg}$ in addition to habitual dietary iron intake.

these reference values, it is crucial to check whether the intake data derived from a particular survey are suitable for assessing adequacy. More guidance on this subject and on how to use NNR in this context is given in the complete NNR report.

The average requirement is the value to be primarily used to assess the risk for inadequate intake of micronutrients in a certain group of individuals. The percentage that has an intake below the AR indicates the proportion having an increased risk of inadequate intake.

Long-term intakes below the LI are associated with an increased risk of developing deficiency symptoms. There is a substantial uncertainty in several of these values. Thus, they should be applied with caution and if possible related to clinical and biochemical data. Furthermore, 
intake of nutrients above these values is no guarantee that deficiency symptoms could not occur in single individuals.

It must be emphasised that a comparison with $\mathrm{AR}$ and $\mathrm{LI}$ values can never decide whether intake is adequate or not, it can only indicate the probability that it is. That is because nutrient intake data are not absolutely true values, but are calculated using food composition tables and reported food consumption, both of which have a considerable error margin. Therefore, in order to find out whether an intake of a particular nutrient is adequate, biochemical measurements and thorough dietary assessment are necessary.

\section{Values for the evaluation of high intakes of vitamins and minerals}

For some nutrients, high intakes may cause adverse or even toxic symptoms. Upper intake levels (UL) have thus been established for some nutrients (Table 7). Prolonged intakes above these levels can, for certain nutrients, induce an increased risk of adverse effects (e.g. preformed vitamin A, vitamin $\mathrm{D}$, iron and iodine). For other nutrients the adverse effects may be different and milder, e.g. gastrointestinal problems, interference with the utilization of other nutrients. The upper levels are not recommended levels of intake, but are maximum levels of daily chronic intakes judged to be unlikely to pose a risk of adverse health effects to humans. The upper levels are derived for the normal healthy population, and values are given for adults. For other life stages, e.g. infants and children, specific data may exist for deriving specific values or such values could be extrapolated. To establish whether a population is at risk for adverse effects, the fraction of the population exceeding the UL and the magnitude and duration of the excessive intake should be determined. There is a substantial uncertainty in several of the upper level values, and they must be used with caution for single individuals. UL values do not necessarily apply in cases of prescribed supplementation under medical supervision.

Wulf Becker

Swedish National Food Administration

Box 622

SE-75 I 26 Uppsala

Sweden

E-mail: wube@slv.se 